\title{
Trials, tribulations and diversification
}

The results are in. The world's largest, most concerted evaluation of the impact of herbicide-tolerant (HT) GM crops on farmland biodiversity (see pp. 1418, 1429, 1454) reveals differences in weed and insect densities depending on the crop type and weed killer studied. The fact that these findings are specific to the United Kingdom and to the crops and weed killers used was predictably lost on the UK media, which proceeded to herald the results as a death knell for GM crops. As a result, Tony Blair and his government no longer have the option of fighting GM's corner. There will be no commercial GM plant approvals in Europe now that European authorities can point to the need to conduct trials on environmental impact.

Is this the end for UK plant bioscience? Well, hardly. Very little creative research has been done on HT crops for a decade or more. Yes, there has been a need to transfer the traits to crop species and to propagate seed. And there has been a good deal of passive 'nature study' on the environmental and agronomic effects of GM crops. But the technology that created the HT crops is ancient in research terms, harking back to a time in the 1980s when genetic manipulation in plants was more art than science. HT plants emerged early at least partly because the transferred trait could be used as a selectable marker in the days when gene cloning efficiencies in crops were extremely low.

Indeed, now might be a good time for the United Kingdom's plant biology community to refocus on gaining greater understanding of fundamentally important plant characteristics while the rest of the world works on applications. It may be a good thing for UK plant research to shift its focus from agronomic traits to those of mere (!) scientific interest. A bit of curiosity-driven plant research could be good. A lot would be better. And if the UK government really wants to get out of this mess, it could certainly do worse than backing innovative UK plant biology right now.

\section{Beyond belief}

As those in biotech are well aware, there are attendant risks in any venture. Beyond Therapy is a case in point.

We must first, of course, define Beyond Therapy. Some may think Beyond Therapy is an epithet for the behaviorally unconstrained; others that it is a new action comedy movie starring Robert de Niro and Billy Crystal. Not so! Rather-and this is restricted by our terms of reference and not by our filmic proclivities-the Beyond Therapy we are considering is Beyond Therapy: Biotechnology and the Pursuit of Happiness, a report from US President George W. Bush's Council on Bioethics published in October (see p. 1417).

One risk in protracted exposure to any publication, whether or not it has as many pages as Beyond Therapy, is that readers may assimilate its style and subsequently — but unintentionally—reproduce it in writing of their own. We considered this_-among many other perils—but were, on balance, persuaded that decisions about whether to read the report should extend beyond the relatively narrow circle of bioethics professionals into the larger arena of this journal's subscribers.

Another risk is that despite visiting the Council's website (http:// www.bioethics.gov/reports/beyondtherapy/index.html) and downloading the document, Nature Biotechnology readers might not read it. It is not our place to speculate upon whether they would find anything of consequence if they did. Neither will we recommend that they should, or should not, take either course of action, both of which are equally justifiable within their separate decision frameworks and which, in any eventuality, are likely to depend more on readers' personal assessments of practical aspects of bandwidth and hard-disk space.

Fundamentally, Beyond Therapy posits that biotechnology-of a rather amorphous and ill-defined type-poses new ethical problems through its potential to offer human enhancement. Unadorned, the report's central thesis appears to be that it is acceptable for biotechnology to provide therapies and diagnosis for medically defined conditions, but morally dubious for individuals to use future biotechnologies to induce in themselves mental states of happiness or satisfaction, or to improve some element of physical performance. Why? Apparently biotechnology for enhancement is dehumanizing because sadness and yearning and acceptance of physical limitations are indispensable elements of what it means to be human.

The report also fails to clarify why it has singled out biotechnology in particular. It apparently is unconcerned about hair transplants, steroid use by athletes, teeth capping, breast implants, tummy tucks and nose jobs, all of which are enhancements and none of which rely on biotech. If it is human dignity we are concerned with, then surely fashion clothes and footwear, reality TV and badly fitted wigs would be more appropriate fodder for ethical scrutiny.

Can we say then definitively, or even with some level of certainty (albeit not an irreproachable one), that Beyond Therapy will enhance our appreciation and comprehension of the ethical dimensions of the potential uses of biotechnology? The answer may be 'no'. Or it might be 'yes'. To decide between the two would require a deeper understanding of what humanity understands by 'enhancement'.

To read Beyond Therapy is to acknowledge that there are times when it is entirely appropriate to craft intricate and verbose prose that weaves wafting and transient thoughts within a fabric of otherwise discontinuous - even disconnected-but nevertheless substantial references to real human experiences. Equally, however, and this is probably unarguable, there are times for getting to the damn point. 